\section{$\underset{\substack{\text { hommes } \\ \text { \& migrations }}}{ }$}

\section{Hommes \& migrations}

Revue française de référence sur les dynamiques

migratoires

1306 | 2014

Ecriture et migration

\title{
Entretien avec Léonora Miano, présidente du jury 2014 du prix littéraire de la Porte Dorée
}

\section{Marie Poinsot}

\section{OpenEdition}

\section{Journals}

Édition électronique

URL : http://journals.openedition.org/hommesmigrations/2818

DOI : 10.4000/hommesmigrations.2818

ISSN : 2262-3353

Éditeur

Musée national de l'histoire de l'immigration

\section{Édition imprimée}

Date de publication : 1 avril 2014

Pagination : 110-112

ISBN : 978-2-919040-27-8

ISSN : $1142-852 X$

\section{Référence électronique}

Marie Poinsot, «Entretien avec Léonora Miano, présidente du jury 2014 du prix littéraire de la Porte Dorée », Hommes \& migrations [En ligne], 1306 | 2014, mis en ligne le 06 août 2014, consulté le 22 septembre 2020. URL : http://journals.openedition.org/hommesmigrations/2818; DOI : https:// doi.org/10.4000/hommesmigrations.2818

Ce document a été généré automatiquement le 22 septembre 2020.

Tous droits réservés 


\title{
Entretien avec Léonora Miano, présidente du jury 2014 du prix littéraire de la Porte Dorée
}

\author{
Marie Poinsot
}

\section{NOTE DE L'ÉDITEUR}

Léonora Miano accompagne le prix littéraire de la Porte Dorée depuis les tout débuts : elle faisait partie du jury de la première édition en 2010. La voilà quatre ans plus tard présidente du jury. L'œuvre de cette jeune femme née à Douala, au Cameroun, est composée à ce jour de sept romans, deux recueils de textes courts, un texte théâtral et un recueil de conférences. A l'automne dernier, elle a reçu le Prix Femina pour son dernier roman, La Saison de l'ombre (Grasset).

Hommes \& migrations : Pour quelles raisons avez-vous accepté de présider le jury du prix de la Porte Dorée ? En quoi ce prix est-il singulier, important pour vous?

Léonora Miano: Ce prix littéraire aborde sa cinquième édition et va devenir important. La thématique qu'il porte n'est pas mon premier intérêt. Je crois même qu'il faudrait l'ouvrir non pas seulement aux textes qui parlent d'exil mais à des profils d'auteurs ayant vécu la migration, même s'ils n'en parlent pas dans leurs romans. Il pourrait s'intéresser à des textes différents, qui parlent d'altérité, d'ici ou d'ailleurs. Ce prix littéraire vise avant tout à mettre en valeur de bons textes. Il s'agit d'abord de littérature et le thème de l'immigration ne doit pas faire oublier la qualité du travail d'écriture. Il s'agit de révéler des auteurs qui n'auraient peut-être pas été remarqués autrement. L'intérêt de ce prix réside, à mes yeux, dans la découverte possible d'autres univers. 
HetM : Cette année, huit titres ont été retenus pour la sélection. Comment avez-vous trouvé cette nouvelle moisson?

L. M. : C'est une édition de très bon niveau. Il n'a pas été facile de départager les ouvrages. La plupart des auteurs ont des univers très marqués. Leur traitement de la thématique de l'exil et des migrations est toujours singulier. Il n'y avait rien de convenu dans les romans sélectionnés. Face à des paroles et à des esthétiques si différentes, le jury ne peut faire que des choix éminemment subjectifs.

HetM : Dans le contexte actuel de montée des incompréhensions et d'un débat conflictuel sur l'immigration, ce prix de la Porte Dorée a-t-il une résonance particulière ?

L. M.: C'est le cas tous les ans, même si cette crispation sur les thèmes liés à l'immigration atteint une sorte de paroxysme aujourd'hui. Depuis cinq à six ans, la situation du pays est préoccupante à cet égard. La mise en lumière de textes qui abordent cette question de manière sensible et profondément humaine devient plus que jamais nécessaire. Dès le début, ce prix a su révéler des textes véhiculant un propos fort, au-delà de leurs qualités esthétiques. J'espère qu'il aura de plus en plus d'audience et sera prescripteur dans les années qui viennent.

HetM: A-t-il été difficile de choisir un lauréat? En quoi le roman primé vous a personnellement touchée?

L. M. : Le roman primé, Georgia de Julien Delmaire (Grasset), était déjà mon coup de cœur à la rentrée littéraire 2013. De tout ce que j'ai lu à ce moment-là, c'est le texte qui m'a le plus touchée. D'abord par la puissance de son souffle poétique. Julien Delmaire travaille une très belle langue. Certains la trouvent trop sophistiquée, mais moi j'aime ça. J'aime qu'on écrive vraiment. Georgia met en présence des figures humaines abîmées, extrêmement différentes. On n'image pas que leur rencontre soit possible. Il est question d'amour, de quelque chose qui transcende la couleur, l'origine.

J'ai été sensible à la musicalité de ce texte. Vous évoquiez tout à l'heure le climat actuel sur l'immigration. Ce roman évite les bons sentiments, il travaille sur la marginalité de manière à interroger ce qui est central dans la société. Ce sont les périphéries qui renseignent le mieux sur le centre. Une société se connaît mieux à travers l'auscultation de ses marges. Bien sûr, on préférerait une lecture plus confortable, qui fasse sourire et donne l'impression que les choses vont aller très vite bien. Ce n'est pas le cas avec le roman de Julien Delmaire qui est dans une approche très réaliste. En même temps, sa poésie, son onirisme à la fois sombre et étincelant balaient tout. C'est cela qui m'a ravie.

C'est le premier roman d'un auteur qui vient de la poésie et du slam, et qui va encore évoluer. C'est très bien que le prix de la Porte Dorée le saisisse à cette étape de son parcours, lui témoigne de l'intérêt et l'accompagne. Ce n'est pas facile de consacrer sa vie à la littérature, à l'art, ce que fait Julien Delmaire. Je ne trouve que des qualités à son roman. C'est un objet rare.

HetM: De quelle manière les écrivains sélectionnés font-ils évoluer la langue française? Comment revisitent-ils les codes esthétiques et la narration classique du roman?

L. M. : Tous les écrivains s'attachent à trouver, dans la langue commune, une langue d'auteur qui soit la leur. Ce n'est pas forcément par des apports au lexique, ni même par la présence d'autres cultures dans le texte, qu'ils font évoluer la langue. Par exemple, Louis-Philippe Dalembert (Ballade d'un amour inachevé, Mercure de France) 
met un point d'honneur à utiliser la langue française la plus classique qui soit. Fabienne Kanor, dans Faire l'aventure (JC Lattès), adopte un ton qui s'adapte à ce roman mais peut être différent pour un autre texte. Elle a raison de le faire. C'est une question de rythme qui lui appartient en propre. Julien Delmaire cherche ce que l'on peut apporter de nouveau à la forme romanesque. Ce n'est pas une quête nouvelle finalement. Le Nouveau Roman amenait déjà une autre vision. Pour l'écrivain haïtien Frankétienne, le roman, tel que conçu en Europe, ne convenait pas à sa sensibilité caribéenne. Aussi a-t-il inventé une forme qu'il a baptisée « la spirale ».

Les auteurs peuvent créer de nouvelles structures et les nommer, mais chacun cherche sa manière de raconter des histoires. Chacun met en place un dispositif qui lui permet de présenter un univers personnel qui corresponde à une géographie intérieure. C'est la base du travail d'écrivain. Ce n'est pas le sujet qui rend les textes particuliers. La littérature ne propose pas de nouveaux sujets, l'humanité n'ayant pas tellement changé depuis l'Antiquité. La singularité est à rechercher du côté de la voix que fait entendre l'écrivain. La recherche formelle se fait en dehors du thème choisi. Chez certains auteurs, dont je fais partie, le signifiant influe beaucoup sur le signifié. C'est-à-dire que l'histoire racontée impose sa forme. Tous les écrivains ne voient pas les choses ainsi et peuvent effectuer une recherche formelle pure, ce qui est une bonne chose. C'est le cas chez Delmaire, qui est un esthète avant tout. C'est vraiment un auteur à suivre, comme Alice Zeniter ( $1^{\text {re }}$ lauréate en 2010 pour Jusque dans nos bras, Albin Michel), dont la carrière démontre que le prix littéraire de la Porte Dorée a eu raison de la révéler.

HetM: Ces romans ne donnent-ils la voix aux migrants qui sont si peu présents individuellement dans les médias et les discours sur l'immigration?

L. M. : Je voudrais répondre oui et, en même temps, je crains de formuler une telle réponse parce que les textes de fiction ne doivent jamais être lus comme des documents. Bien sûr, ils nous présentent quelque chose qui ressemble à notre réalité mais ils émanent d'abord d'un parcours et d'une personnalité qui ne doivent pas être minorés. Fabienne Kanor fait-elle entendre la voix de ceux dont elle n'a pas vécu ellemême l'histoire? Ou bien montre-t-elle que ces parcours qui ne sont pas siens l'intéressent et qu'elle est touchée par ces figures? Cela me suffit. À chacun d'aller prendre contact avec ces réalités et d'aller les entendre véritablement. Julien Delmaire nous fait-il entendre la voix d'un sans-papiers? Je pense qu'il restitue quelque chose qu'il a perçu, lui. Ses engagements sociaux l'ont amené à soutenir des associations d'aide aux sans-papiers.

Aucun de ces auteurs n'aurait envie d'être présenté comme un porte-parole ou même un porte-voix. Ce serait trop lourd. Ces textes nous ouvrent sur des réalités qui parfois nous échappent mais ils restent des invitations à aller voir. Surtout, ne les lisons pas comme s'ils étaient des espèces de témoignages. Nous passerions à côté du travail de création, qui est la chose la plus importante. Les auteurs nous font traverser un pays de l'imaginaire qui ressemble à celui que nous connaissons et c'est pour cela que nous nous y attachons. C'est la noblesse du travail littéraire: la création.

\section{La sélection 2014 , 5e édition}

Isabelle Condou, Un pays qui n'avait pas de port, Plon 
Louis-Philippe Dalembert, Ballade d'un amour inachevé, Mercure de France

Julien Delmaire, Georgia, Grasset

Faïza Guène, Un homme, ça ne pleure pas, Fayard

Fabienne Kanor, Faire l'aventure, JC Lattès

Guy Scarpetta, Guido, Gallimard

Shumona Sinha, Calcutta, L'Olivier

Carole Zalberg, Feu pour feu, Actes Sud

\section{Les membres du jury}

Léonora Miano, écrivain

Yvan Amar, linguiste, journaliste culturel, RFI

Nathacha Appanah, écrivain

Arlette Farge, historienne

Michaël Ferrier, écrivain

Mustapha Harzoune, critique littéraire

Oriane Joncourt-Galignari, écrivain, rédactrice en chef des pages littéraires de Transfuge

Emmanuel Kherad, journaliste culturel, France Inter

Isabelle Quentin-Heuzé, Fondation EDF

Jacques Toubon, président du conseil d'orientation de l'Établissement public du palais de la Porte Dorée

Sébastien Wespiser, libraire, Le Thé des écrivains, Paris IV

Des secondes du lycée Élisa-Lemonnier (Paris XII) et du lycée Jean-Zay (Aulnay-sousBois, 93) et des étudiants de l'université de Paris XIII

\section{AUTEUR}

\section{MARIE POINSOT}

Rédactrice en chef de la revue 